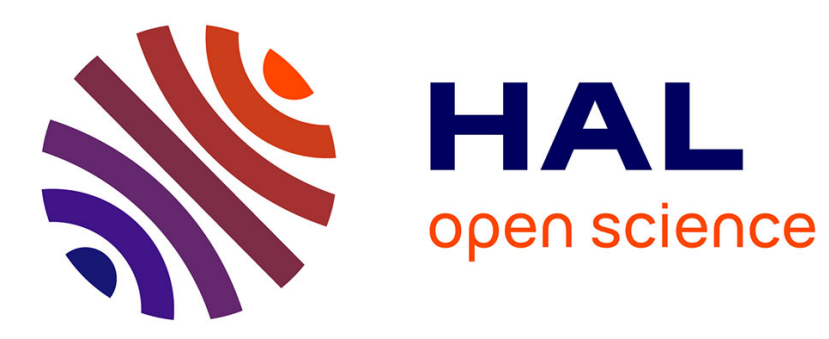

\title{
Did Euclid Prove Elements I, 1? The Early Modern Debate on Intersections and Continuity
}

\author{
Vincenzo de Risi
}

\section{To cite this version:}

Vincenzo de Risi. Did Euclid Prove Elements I, 1? The Early Modern Debate on Intersections and Continuity. Reading Mathematics in the Early Modern Europe. Studies in the Production, Collection, and Use of Mathematical Books, ed. P. Beeley, Y. Nasifoglu, B. Wardhaugh, London, Routledge 2020, pp. 12-32., pp.12-32, 2020, 9780367609252. hal-03059615

\section{HAL Id: hal-03059615 https://hal.science/hal-03059615}

Submitted on 12 Dec 2020

HAL is a multi-disciplinary open access archive for the deposit and dissemination of scientific research documents, whether they are published or not. The documents may come from teaching and research institutions in France or abroad, or from public or private research centers.
L'archive ouverte pluridisciplinaire HAL, est destinée au dépôt et à la diffusion de documents scientifiques de niveau recherche, publiés ou non, émanant des établissements d'enseignement et de recherche français ou étrangers, des laboratoires publics ou privés. 


\section{Did Euclid Prove Elements I, 1? The Early Modern Debate on Intersections and Continuity}

Vincenzo De Risi

\section{The Theory of Intersections in Geometry}

In this chapter, I explore an important and yet neglected episode in the history of the foundations of mathematics, and its relations with the transmission and transformation of the text of Euclid's Elements: the early modern debate on the continuity of geometrical figures and the theory of intersections in elementary geometry.

As is well known, at the end of the nineteenth century the mathematician Moritz Pasch criticized Euclid for having assumed without justification the existence of the points of intersections between the lines and circles that he traced in his constructions. Pasch pointed his finger at the very first proposition of the Elements, the one showing how to construct an equilateral triangle on a given segment. In it, Euclid draws two equal circles at the two ends of the given segment, each having as radius the segment

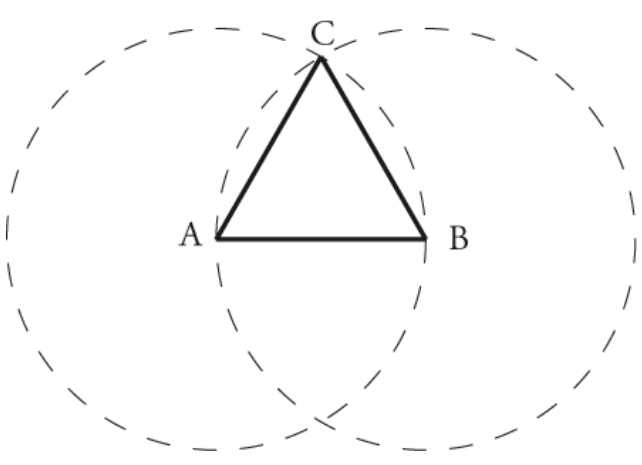
itself, and then conjoins the ends of the segment with a newly found point at the crossing of the two circles. Euclid had been careful in spelling out the assumptions needed to perform such a construction: to draw circles with any center and any radius (Postulate 3), to draw straight lines between two given points (Postulate 2), to compare equal segments with equal segments (Common Notion 1; Definition of a Circle). Yet, he overlooked (or so claimed Pasch) a most important assumption, viz., that the two crossing circles do indeed intersect one another, so that their point of intersection exists. Pasch accused Euclid of relying on his eyes rather than upon his mind, pretending that he was to see in the diagram the existence of such a point. In Pasch's mind, however, the foundation of mathematics 
demanded stricter, propositional standards of rigor: the task of modern axiomatics, Pasch said, consisted in filling this and like gaps in Euclid's proofs, by introducing to this effect all the necessary axioms. ${ }^{1} \mathrm{~A}$ few years after Pasch, Hilbert provided such axioms in his celebrated Grundlagen der Geometrie (1899), and since then no axiomatization of geometry can dispense with some principles about intersections and continuity. They often take the form of the so-called Line-Circle and Circle-Circle intersection axioms:

If a straight line has one point inside a circle, the line will meet the circle.

If one of two circles has one point inside the other and one point outside it, the two circles will meet.

These principles are in fact sufficient to ground the whole theory of intersections in elementary Euclidean geometry. ${ }^{2}$ It is often claimed that the outstanding developments in abstract mathematics in the nineteenth century engendered Pasch's (and others') new foundations of geometry, and their general distrust in diagrammatic inferences. An axiomatization of the theory of continuity in elementary geometry would accordingly mark the divide between a modern, formal approach to mathematics and the ancient 'intuitive' way of doing geometry with diagrams.

Even if there may be elements of truth in that claim, the actual historical situation seems to be far more complicated. In particular, we find that Pasch's criticisms about a missing continuity assumption in Elements I, 1 were by no means original with him. On the contrary, early modern mathematicians had discussed demonstrative gaps in this proof from the renewal of the study of geometry in the Renaissance, and had already pointed out that the Euclidean demonstrations had to be complemented by a Line-Circle or CircleCircle intersection axiom. Although nowadays these early modern foundational discussions have been almost forgotten - thereby allowing Pasch to retain his place as the author of a small revolution in mathematics - they happened in fact to be quite widespread in the sixteenth, seventeenth and eighteenth centuries, when they attracted the efforts of the best mathematicians of that age. I think it is important, therefore, to attempt a history of this foundational debate, and re-evaluate the reasons and aims that led to the introduction of continuity principles in geometry.

It should be stressed that the discussion of the theory of intersections in elementary geometry is indeed an early modern accomplishment: it long predates Pasch, but it had not yet been developed in antiquity or in the Middle Ages. We possess quite a number of ancient and medieval commentaries on the Elements, or fragments thereof (by Heron, Pappus, Proclus, Simplicius, and then al-Nayrīzī, Thābit ibn Qurra, ibn al-Haytham, Omar Khayyām, Nasīr ad-Dīn at-Tūsī, and further Albert the Great, Thomas Bradwardine, and others) that report several objections to Euclid's proofs - including several objections to Elements I, 1 - but none of these detected any problem about the existence of intersection points. In this respect, the demonstrative gaps in the theory of intersections denounced by the modern mathematicians had been overlooked not just by

\footnotetext{
${ }^{1}$ See Moritz Pasch, Vorlesungen über die neuere Geometrie (Berlin: Springer, 1882, 1926), \$6, pp. 44-5.

${ }^{2}$ See Robin Hartshorne, Geometry: Euclid and Beyond (New York: Springer, 2000), pp. 104-16.
} 
Euclid, but by all mathematicians who lived in the two thousand years from the composition of the Elements to the Renaissance. ${ }^{3}$

\section{Axioms and Diagrams}

Indeed, discussion of the theory of intersections seems only to originate in the sixteenth century. This change in attitude is to be understood within a more general renewal of axiomatics that took place in the early modern period. Foundational discussions in the Middle Ages had in fact seldom dared to add new axioms to the Euclidean system, and the first printed editions of the Elements in the Renaissance were mostly concerned with better understanding the ancient mathematical text, and with providing a reliable edition thereof. It was indeed only in the first half of the sixteenth century that a few mathematicians felt bold enough to rework the system of principles inherited from Euclid by adding a few new axioms that they believed necessary to ground the propositions of the Elements. While in the following decades advancements in this respect remained tentative and rather timid, at the turn of the seventeenth century the new axioms began to increase in number, and in the course of the following century several hundred such axioms were devised and added to the Elements. ${ }^{4}$

This remarkable ease in adding new axioms into the Euclidean corpus was probably grounded on the widespread early modern view that the axioms themselves should not be considered as unproven assumptions but rather as statements flowing from the definitions of the terms involved. The latter idea had been widely discussed in Scholastic philosophy, and it was generally accepted that, for instance, the axiom stating that only one straight line may be drawn between two points should rest, in the end, on the definitions of a straight line and a point. This conception of axioms as derivative statements (rather than starting points) pushed early modern mathematicians towards a remarkable enlargement of the axiomatic basis of geometry, for they were under the impression that their additions were changing nothing substantial in the foundations of this science. The introduction of new axioms was generally seen as a way of making explicit the consequences of the Euclidean definitions of the geometrical terms, and offering some further statements that might be useful in the proofs.

This seems to have been the case with the axioms on intersections as well, and the latter were seen by several early modern mathematicians as grounded on the notions of continuity and magnitude. Aristotle, in fact, had defined geometry as the science of magnitudes (Greek $\mu \varepsilon \gamma \varepsilon \theta \eta$ ), and had further defined magnitudes as continuous quantities: as opposed to numbers, which he regarded as discrete quantities. This definition was almost

\footnotetext{
${ }^{3}$ In order to account for the missing thematization of continuity in Greek geometry, I have offered a tentative reconstruction of Euclid's theory of intersections, that may explain why no further Greek author felt compelled to investigate the issue any further. See Vincenzo De Risi, 'Gapless Lines and Gapless Proofs. Intersections and Continuity in Euclid's Elements,' Apeiron, 2020.

${ }^{4} \mathrm{I}$ offered a list of the axioms introduced in the Elements in the early modern era in Vincenzo De Risi, 'The Development of Euclidean Axiomatics. The systems of principles and the foundations of mathematics in editions of the Elements from Antiquity to the Eighteenth Century,' Archive for History of Exact Sciences 70 (2016), pp. 591-676.
} 
universally accepted in the Middle Ages and the early modern age, and therefore the objects of Euclidean geometry, such as circles, lines, polygons, or other figures, were usually simply referred to as 'magnitudes' and regarded as continuous wholes. It comes as no surprise, thus, that some axioms on intersections were added to the Elements, for these axioms were in turn regarded to be grounded on, and justified by, the definition of a geometrical object as a continuous quantity. This had not happened in antiquity, for neither Euclid, nor Archimedes, nor any other classical geometer had ever defined the objects of their science as 'continuous' in any sense. These geometers, moreover seem to have not endorsed the above-mentioned notion of an axiom as derivative from a definition. It was therefore only the development of a new epistemology of axioms in the Middle Ages, coupled with the Aristotelian idea that geometrical objects are continuous by definition, that allowed early modern mathematicians to state new axioms on intersections.

It may be remarked that very few of the newly introduced axioms could actually be derived from the given definitions, and it would be hard, if not impossible, to try to prove - for example - that only one straight line passes through two points starting from the very obscure Euclidean definition of a straight line. In this respect, early modern mathematicians simply accepted the received epistemological view that the proof was possible in principle, and rarely bothered to spell out the actual derivation explicitly. Similarly, the notions of continuity generally accepted in the early modern age were still the Aristotelian ones, or some Scholastic variation thereof, no more adequate to ground a theory of intersections in geometry. ${ }^{5}$ The quest for a notion of continuity that could be used in mathematics had to wait for further efforts. Even in today's axiomatization of elementary geometry, indeed, the above-mentioned Line-Circle and Circle-Circle intersection principles are often introduced with the aim of dispensing from a general definition of continuity (such as Dedekind completeness, for instance).

We may notice that the introduction of the intersection axioms was not immediately related to issues about rigour or distrust of 'intuition', but rather to a transformation of mathematical epistemology grounded on the interaction between the Euclidean and the Aristotelian traditions. It is also the case that certain important changes in diagrammatic practices played a role in the acceptance of intersection principles in the early modern age. Yet I think it can be proven that the latter were not the first or the most important reasons for introducing such principles: for apparently no one in the sixteenth century questioned the validity of diagrammatic inferences, nor the 'immediate evidence' of the existence of the intersection points in Elements I, 1, as is provided by a glance to the drawing. In the following century, on the other hand, we do find several attempts to relieve geometry of its constant recourse to intuition, and to reduce (if not to eliminate altogether) reference to diagrams. In short, in the seventeenth century some mathematicians tried to offer a purely propositional approach to geometrical proof. The reasons behind so important a change in mathematical practice, which was to reshape the outlook of elementary geometry deeply, and produce innumerable epistemological discussions in the early modern age, are numerous and varied. I will not try to account for them in the present chapter, but we should at least mention the growing pervasiveness of algebraic tools in the study of

\footnotetext{
${ }^{5}$ I have argued for this claim in De Risi, 'Gapless Lines'. Today's readings of Aristotle's definition of continuity in modern mathematical terms tend to compare it with the topological notion of connectedness, and the latter is not adequate, in any case, to ground a theory of intersections. See for instance Michael J. White, 'On Continuity: Aristotle versus Topology?', History and Philosophy of Logic 9 (1988), pp. 1-12.
} 
geometry after the Cartesian revolution, and the propositional thematization of spatial properties in the same decades. In any case, all these changes long predated the nineteenthcentury 'crisis of intuition' in mathematics, to which Pasch referred, and which is usually regarded as the first expression of such foundational worries.

The willingness to offer a purely propositional proof of some Euclidean theorems, including Elements I, 1, had as a consequence that several early modern geometers had to integrate Euclid's demonstration not only with an intersection axiom, but also with a lengthy discussion of the relative position of the two circles. The intersection axioms are in fact conditional statements, stating that two circles (for instance) will intersect if they have some points inside and some points outside one another. The propositional antecedent of the axiom should therefore be proven before it can be applied to Elements I, 1 in order to demonstrate the existence of the intersection points. Euclid had not done so, plainly relying on inspection of the diagram to ascertain the relative position of the two circles. Early modern geometers who wanted to prove the same theorem in a purely propositional way therefore had to modify Euclid's proof, and argue that the two circles are in such a position as to have some points inside and some points outside one another. In order to do this, these geometers had to innovate significantly, and often to introduce new relations (such as to-be-inside or -outside) that were not made explicit by Euclid himself. In short, a few topological notions were thus first introduced into elementary geometry.

The introduction into the domain of mathematics of such topological and positional elements was by itself a remarkable transformation of the discipline, and would produce even more important changes in the centuries to come (with the development of projective geometry). In some cases, such positional discussions were regarded by early modern mathematicians as more important than the intersection axioms themselves, since the latter, as we have seen, were generally meant to be mere consequences of the definitions of continuity and magnitudes. The study of the changing proof of Elements I, 1 therefore offers an outstanding vantage point from which to investigate several aspects of the transformation of Greek geometry into modern geometry: the notion of an axiom, the definition of continuity, the role of diagrams in demonstrations, the birth of a geometry of position. It is thus worthwhile to follow this history carefully throughout the early modern age, and try to disentangle the various components and spell out the various contributions that eventually produced a modern proof of the ancient theorem.

\section{Oronce Fine and the sixteenth century}

To the best of my knowledge, the first Renaissance geometer to add a number of postulates to elementary geometry was the mathematician and cosmographer Oronce Fine (1494-1555). ${ }^{6}$ Remarkably enough, these new principles concerned nothing but intersections. Although in the course of the following centuries a great many new axioms were added to the Elements with the intention to explicitly ground ordering, congruence, motion, parallelism and so forth, the issue of intersections (already at stake in Elements I, 1)

\footnotetext{
${ }^{6}$ For an extensive overview of Fine's work in several fields, and its connection with the mathematical studies of the time, see Angela Axworthy, Le Mathématicien renaissant et son savoir. Le statut des mathématiques selon Oronce Fine (Paris: Garnier, 2016).
} 
was clearly recognized and singled out by Fine as the most obvious failure of Euclid's deductive system and, accordingly, as the first blemish that needed to be emended. To this end, in his most important Protomathesis (Paris 1532), Fine added two new postulates to the five classically attributed to Euclid. The first one (i.e. Fine's Postulate 6) stated that

If a straight or curved line is drawn from a point which is within a figure to another point in the same plane which is outside the figure, it will intersect the sides or boundary of the figure,

whilst the second postulate (Postulate 7) claimed that

If a straight line drawn from any angle of a rectilinear figure meets the opposite side or angle of the figure, it also intersects this latter side or angle. ${ }^{7}$

Fine commented on the first of these postulates by pointing out that there was no continuous transition between the extremes that did not pass through the medium, ${ }^{8}$ and also by referring his readers to a diagram, which made it easy to see that this was indeed the case. He then went on to remark, in a fairly general way, that the two postulates, despite being evidentissima in themselves, needed nonetheless to be explicitly spelled out, as they were necessary to prove the first demonstrations of Euclid. Fine concluded that an almost infinite number of such extremely evident principles might be devised, so that he would not (and he did in fact not) bother to state explicitly all the other principles in question.

Fine's Protomathesis is a curious piece of work, which states the principles required for elementary geometry but then only proves a very few scattered theorems of Euclid, the ones that Fine found especially important for the other applied mathematical disciplines discussed in the volume. Elements I, 1 is not among the propositions proven, so that Fine never made use of his important intersection principles in the work in which they had first been stated. A few years later, however, Fine was to publish his own edition of the first six books of Euclid's Elements (Paris 1536). In this edition - largely drawn from Bartolomeo Zamberti's Latin translation (Venice 1505) - no new postulates on intersections were added, probably also for the sake of philological fidelity to the Euclidean text. Yet, in the proof of Elements I, 1, Fine remarked that the two circles (as in Figure 1.1) do indeed intersect one another, since one of the two circumferences is partly inside and partly outside the other one. Fine offered no proof for the latter statement regarding the relative position of the circles, and instead relied on the mere inspection of the diagram. As is straightforward to realize, Fine's inference that such a point of intersection exists clearly depends on the above-mentioned Postulate 6 of the Protomathesis, although in his Euclid edition Fine did not make it explicit. ${ }^{9}$ As for Fine's Postulate 7, it is actually assumed by Euclid a good number of times in the first book of the Elements. Fine, however, did not make it explicit in his own Euclidean edition.

\footnotetext{
${ }^{7}$ Oronce Fine, Protomathesis (Paris: 1532), p. 54v: '6. Rectam vel obliquam lineam, à dato puncto quòd intra figuram est, ad exterius quodcunque punctum in eodem plano signatum eductam: ipsius figurae latera, vel ambitum intersecare. [...] 7. Rectam lineam à quovis rectilinearum figurarum angulo, in oppositum vel latus vel angulum incidentem: utrunque $\&$ angulum $\&$ latus dividere.'

${ }^{8}$ Fine's passage seems to be reminiscent of statement in Proclus, In Primum Euclidis, 234 Friedlein.

${ }^{9}$ Oronce Fine, In sex priores libros geometricorum elementorum Euclidis Megarensis demonstrationes (Paris: Simon de Colines, 1536), p. 11.
} 
It is difficult to state exactly the content of Fine's new axioms of intersection in modern terms. His Postulate 6 seems clearly to be an instance of the Circle-Circle intersection axiom, and it is certainly employed in this way in the course of the Elements. It should be noted, however, that Fine (like many other early modern geometers after him) stated the principle with reference not to circles but rather to figures in general. Such a notion is rather vague in elementary geometry, Euclid having defined a figure $(\sigma \chi \tilde{\eta} \mu \alpha)$ as something which 'is contained by any boundary or boundaries'. The thrust of the definition seems to be that a figure is something which is closed, thereby permitting us to distinguish between an interior and an exterior. Such notions, however, are probably too general to convey the intended Euclidean meaning of the word, and the ancient geometer rather offered an explicit list of the figures he discussed in the Elements (in plane geometry, mainly polygons and the circle). Should we restrict Fine's axiom to the figures explicitly defined in the Elements, its meaning would coincide with the Circle-Circle intersection property. The same would apply were we to take 'figure' to mean any kind of closed configuration that is susceptible of being produced (as is always the case in the Elements) by ruler-and-compass constructions. In any case, I am not aware of any early modern mathematician who employed a similar principle (i.e. a principle referring to 'figures' in general) to ground the intersections between higher order curves (such as conic sections), or figures that exceeded the class of those thematized in the Elements.

We have no information about what motivated Fine to reshape the deductive system of Euclid, nor about where exactly he drew his inspiration from. The Protomathesis axioms seem to be justified by some naïve notion of continuity (no explicit account of which Fine provided in any of his definitions), and the tacit assumption that geometrical figures should be considered to be continuous. As a matter of fact, Fine characterized the basic geometrical objects by describing their generation through motion (the circle, for instance, being the line traced by the rotation of a segment around one of its ends), and the latter procedure seems to entail their continuity. ${ }^{10}$

On the other hand, Fine seemed not concerned at all with the question of propositional rigor, or with distrust of diagrammatic inferences. We have seen that he used a reference to the diagram to explain the validity of his intersection principles, rather than the other way around. In both the Protomathesis and his edition of the Elements, indeed, Fine showed no qualms about recurring to diagrams to draw geometrical consequences. It seems clear, therefore, that the first introduction of intersection axioms in the history of geometry was not caused by any suspicion of the role of 'intuition' in the discipline.

In any case, Fine's remarkable feat in axiomatics remained isolated and his work on the topic went almost completely ignored by subsequent generations. Fine's decision to split the demonstration between two different volumes (putting the axiom in the 1532 Protomathesis, and the proof of Elements I, 1 in the 1536 Elements) surely damaged the reception of his views. Even French authors, largely influenced by Fine in other aspects of their work, neglected the axiomatics of the Protomathesis.

\footnotetext{
${ }^{10}$ At the beginning of the list of definitions in the Protomathesis, Fine stated that he was dealing with continuous quantity (p. $50^{\mathrm{v}}$ ), then he defined a line as the 'intelligible flow' of a point, and characterized the circle as produced by the rotation of the segment (p. 51 ${ }^{\mathrm{r}}$ ). In his edition of the Elements, he defined a line as the product of the fluxus or motus transumptivus of a point, and the circle by rotation. The Aristotelian definition of geometry as a science of continuous quantities is here asserted already in the dedication to the King of France, in the very first page of the book.
} 
I have, however, been able to find traces of Fine's influence on Pedro Juan de Lastanosa de Monzón (1527-76), a Spanish mathematician, engineer and cartographer. In his early years Lastanosa travelled in Flanders, and it was apparently there that he came to know of Fine's works on geometry. In 1553 Lastanosa wrote, but did not publish, Los dos libros de géometria practica, which were nothing but a Spanish translation of the two books dedicated to geometry of Fine's Protomathesis. ${ }^{11}$ Back in Spain to work at the court of Philip II, Lastanosa published a booklet in Latin, the Elementa Arithmeticae ac Geometriae (Valencia 1569), that stated as its Postulate 6 nothing but Fine's first intersection principle. Lastanosa, however, did not comment any further on the subject, nor did he employ the postulate in proving Elements I, 1, thereby making no advancement beyond Fine. ${ }^{12}$

Lastanosa's book - by itself not so major an accomplishment - together with plenty of other essays and treatises on elementary geometry published in the second half of the sixteenth century, were however all soon to be eclipsed by Christoph Clavius's edition of Euclid (Rome, 1574). ${ }^{13}$ This masterful edition by the Jesuit professor of the Collegio Romano represented for centuries the largest repository of comments and alternative proofs for the Elements, that Clavius had collected from dozens of ancient, medieval and Renaissance sources. Clavius, however, did not mention Fine's Protomathesis nor, more generally, did he appear to have seen the existence of the point of intersections as an issue in the proof of Elements I, 1. As a matter of fact, Clavius even attempted a quasi-formal proof of this proposition, reshaping it into syllogistic form following the example of the works by Alessandro Piccolomini (1547) and Herlin and Dasypodius, who had reduced Euclid to Aristotelian logic. ${ }^{14}$ Neither Clavius nor his predecessors, however, noticed that the chain of deductions had a gap in establishing the existence of the point of intersection. In the last analysis, their proof, however reshaped in forma and therefore more explicit in its logical connections than the original Greek one, still relied on diagrammatic inferences. Herlin and Clavius in fact had no ambition to reduce a Euclidean demonstration into a

\footnotetext{
${ }^{11}$ Lastanosa's Spanish translation of Fine was made in collaboration with Jeronimo Girava, and is preserved in manuscript in the Biblioteca Nacional de Madrid (Manuscrito 9437). It has been studied by N.G. Tapia and M.I.V. Maroto, 'Los Dos Libros de Géometria Practica de Fineo, Traducciones por Girava y Ordenados por Lastanosa', Asclepio 41 (1991), pp. 247-67.

${ }^{12}$ Pedro Juan de Lastanosa de Monzón, Elementa Arithmeticae ac Geometriae (Valencia: Huete, 1569), quotes ad literam Fine's postulate on page 45.

${ }^{13}$ Christoph Clavius, Euclidis elementorum libri XV (Roma: Vincenzo Accolto, 1574). A second, substantially modified edition was published in 1589 , followed by several others in Clavius's life. The last one dates from 1612.

${ }^{14}$ See the proof offered in Alessandro Piccolomini, In mechanicas quaestiones (Roma: Blado 1547), and in Christian Herlin and Konrad Dasypodius, Analyseis geometricae sex librorum Euclidis (Strasbourg: Rihel, 1566), and the reworking of the former in Clavius, Euclidis elementorum. Such a proof was often repeated in later editions of the Elements. An alternative formal proof of Elements I, 1 was also given by Pierre Herigone in his Cursus mathematicus. Cours mathematique (Paris: Le Gras, 1634); Herigone, however, silently assumed, as had his predecessors, the existence of the intersection point of the circles. A further, much more complicated proof was later attempted by Jungius, still relying, however, on diagrammatic inferences. See Vagetius's Admonitio to the second edition of Joachim Jungius, Logica hamburgensis (Hamburg: Rebenlin, 1638, 1681), 6-12; now also in Wilhelm Risse, Joachim Jungius. Logicae Hamburgensis additamenta (Göttingen: Vandenhoeck, 1977), 257-61. The ancient source seems to be Philoponus, In anal. post. 8 Wallies. Leibniz noticed that such syllogistic proofs missed the most important gap in the Euclidean demonstration, that is to say, the existence of the point of intersection: 'Hoc demonstrare quod circuli se secent Euclides et interpretes neglixere, etiam cum in Syllogismos redegere demonstrationem' (Demonstrationes Euclideas, still unpublished in LH XXXV, I, 3, Bl. $2^{\mathrm{r}}$ ).
} 
chain of propositions (much less into a symbolic derivation), but rather the more modest (and yet still unattainable) aim of showing that Aristotelian syllogistic was a viable instrument of proof in geometry. They, like Fine before them, were at perfect ease in drawing conclusions from both logic and diagrams, and probably regarded the existence of the intersection points of circles in Elements I, 1 as immediately granted by the picture.

\section{The seventeenth century}

In the course of the following decades, however, more and more thinkers and geometers did move from the ancient understanding of geometry as a science of figures (like the ones mentioned above) to conceiving of geometry as the science of space and its properties. I have described elsewhere the causes and far-reaching implications of such a shift, which entailed, among other things, the propositional thematization of positional properties (such as the relative position of the circles in Elements I, 1). ${ }^{15}$ The rise and diffusion of algebraic geometry, on the other hand, showed to early modern mathematicians how a geometrical proof might be carried out 'blindly' and without reference to diagrams. As mentioned above, these and other transformations of seventeenth-century geometry brought a few mathematicians to attempt a more propositional, and less diagrammatic, approach to elementary geometry as well. Accordingly, Fine's postulates started to be read with new eyes, and with new problems and concerns in mind.

The beginning of this new, rich season of studies on continuity is to be found in the edition of the Elements by the French Jesuit Claude Richard (1589-1664). Appointed in 1629 Royal Cosmographer of Spain by Philip IV, Richard served in this role for more than thirty years. It is quite probable that Richard was acquainted with the work of the most famous French cosmographer of the previous century well before this appointment. It cannot be ruled out that he learned - or, at least, was prompted to reflect upon - Fine's axioms thanks to Lastanosa's work, well known at the time in Spain.

In the Library of Real Academia de la Historia in Madrid I have indeed been able to find a manuscript by Richard containing his remarks (in Spanish) on the first four books of Euclid's Elements. Among these undated notes, we find no axioms about intersections. But Richard did detect a gap in the Euclidean proof of Elements I, 1. Indeed, he discussed it at length, and attempted to prove the actual intersection of the two circles, based on their relative position. In short, Richard attempted to argue, for the first time, in a purely propositional way that the two circles in Euclid's demonstration are in such a position as to overlap one another. Richard's handwritten commentary on Euclid does have a few diagrams here and there (mainly for explanatory purposes, rather than for actual proof), but most of the theorems are not equipped with any illustration at all. The first page of his notes, dealing with Elements I, 1, shows a compact block of text, with letters referring to points and lines of Euclidean figures, but no diagram or image. Apparently, the entire proof should work without any recourse to intuition.

\footnotetext{
${ }^{15}$ See again De Risi, 'Gapless Lines', and Vincenzo De Risi (ed.), Mathematizing Space. The Objects of Geometry from Antiquity to the Early Modern Age (Basel: Birkhäuser 2015).
} 
Richard concluded the demonstration by stating that that since one circle is partly inside and partly outside the other circle, the two should meet. ${ }^{16}$ The latter consequence clearly does not follow without any further ado, and it is therefore not surprising that when Richard decided to publish his Euclidean commentary, he felt the need to supplement it with an axiom that could mediate between the relative position of the two circles and their actual intersection.

This happened in Richard's Latin edition of the Elements published in Antwerp in 1645. Richard's axiomatization of Euclid was a superabundant example of his century's creativity in the foundational domain. Although taking his cue from Clavius's axiomatization of the Elements (and thus paying homage to the Jesuit master), Richard enriched it enormously, ending up with some fifty axioms more than Euclid. These were devised in order to solve a vast array of foundational problems in geometry, and they dealt extensively with intersections. As a matter of fact, Richard gave no fewer than seven different axioms on intersections between lines and circles. Richard was firmly convinced that all axioms should be proven, and offered therefore several explanations for each of them. Richard's first principle on the topic (his Axiom 22) reads that

If a circumference with a given center and a radius of a given length is drawn, and the radius is extended beyond the center to infinity, it will intersect the circumference. ${ }^{17}$

This principle is in fact weaker than the Line-Circle intersection property, as it only refers to the intersection of a circle with a straight line which is its radius. Richard offered a proof of the principle by appealing to the generation of a circle by the rotation of its radius. Then, however, he inadvertently passed over to proving that a straight line intersects a circle at two points (his Axiom 23), concentrating only on the number of the points of intersection (as Euclid had done in Elements III, 10), and from this to even more axioms. The last of these, which represents the culmination of Richard's axiomatics on continuity, simply states that

If a straight line drawn inside a figure is produced to infinity (if needed) in both directions, it will intersect the boundary of the figure. ${ }^{18}$

This is a straightforward instance of the Line-Circle intersection axiom, duly extended to the boundary of any figure (as in Fine). However weak Richard's explanations of the

\footnotetext{
16 'Centro $B$, intervallo $B A$ se describa un circulo, y centro $A$, intervallo $A B$ se describa otro circulo; este cortara el otro, porque siendo por la definicion 15. La circunferencia del circulo ygualmente distante de su centro $\mathrm{A}$, es menester concibir otra linea recta ygual a la $\mathrm{AB}$ semidiametro deste circulo, haria la parte contraria del puncto B, y como el centro A esta en la circumferentia del otro circulo primero, y este segundo comienca desde $\mathrm{B}$, que es un puncto en el area del circulo primero, y el otro extremo del diametro deste segundo circulo, concibiendo la linea recta BA, ultra A, esta fuera del mismo circulo primero la circumferentia deste segundo circulo saldrá fuera de la area del primero, y assi le cortarà.' (Biblioteca de la Real Academia de la Historia, Colección de Cortes, 9/2680 -568, p. 1v).

${ }^{17}$ Claude Richard, Euclidis elementorum geometricorum libros tredecim (Antwerp: Verdus, 1645), p. 16: 'XXII. Circuli describenda circumferentia ex puncto dato ut centro, \& intervallo dato semidiametri; productam hanc semidiametrum ultra centrum in infinitum, secabit in parte producta.'

${ }^{18}$ Richard, Euclidis elementorum, p. 17: 'XXVII: Recta linea intra figuram aliquam ducta, producta utrimque si opus sit in infinitum, secabit extremum figurae.'
} 
axioms may appear, and however pleonastic all his axioms together may be, Richard was crystal-clear that one of them (his Axiom 26, in particular) was strictly needed to perfect Euclid's proof of Elements I, 1. In the course of the latter proof in the 1645 edition, however, Richard mentioned Axiom 26 as a necessary premise for the demonstration, but did not provide any reasoning about the relative position of the two circles, in this case just pointing to the diagram. Richard's two proofs, therefore - the manuscript one and the published one - addressed two different issues of the Euclidean proof, and aimed at different epistemological goals; but they did not merge together into a propositional, gapless proof of the theorem. Still, it seems that it was through Richard's edition of Euclid that the axiomatization of the theory of intersections first entered into the early modern debate on the foundations of geometry.

Just a very few years after Richard's work was published, John Wallis (1616-1703) pointed out to his students in Oxford that Euclid's treatment of intersections was far from satisfactory. In his lecture on 29 November 1651 - still unpublished - Wallis called attention to the fact that the existence of the points of intersection of the two circles in Elements I, 1 is not warranted by the explicit Euclidean axioms, but is rather accepted by relying on one of the many implicit, and yet unquestionable, geometrical principles grounding the Elements. The truth of such principles, continued Wallis, could be easily grasped by merely inspecting the diagram.

It is not uncommon that also other unwritten principles are assumed in demonstrations (to which one can refer by looking at the diagram). In the present proposition, they are:

The circles so drawn intersect one another; and then and finally

Their intersection is a point;

$[\ldots]$

Lines $A C$ and $B C$ make an angle in point $C$.

But these and similar statements are so well known, that we cannot doubt of them any more than the written axioms.

While we have drawn above two whole circles, with centers A and B, it would have been enough if we had just drawn two arcs however small, provided that they intersect. And this is clearly true also in similar cases. The demonstration, indeed, is not grounded on the whole circumferences more than on the arcs. ${ }^{19}$

It is difficult to ascertain whether Wallis may have been acquainted with Richard's edition of the Elements or Fine's Protomathesis. Wallis in fact spelled out no axiom about intersections. Moreover, he was without question a good enough mathematician to detect the Euclidean gap by himself.

\footnotetext{
${ }^{19}$ Oxford, Bodleian Library, MS Don d 45, p. 46 (John Wallis, 'Praelectiones in Elementa Euclidis'): 'Sed et principia alia non scripta non rarò in demonstrandum supponuntur (quo referri potest illud ex conspectu diagrammatis). Qualia sunt in praesenti propositione, Circulos ita ductos se invicem secari; item sectionem illam in puncto fieri; et tandem lineas $A C, B C$, angulum in ipso puncto $C$ facere; non autem aliquò usque conjunctas manari et tandem separari. Sed haec aliaque ejusmodi effata adeo nota sunt ut de iis non magis dubitare possimus, quam de ipsis scriptis axiomatibus. Cum autem superiùs integros circulos descripsimus, centris $\mathrm{A}$ et B, sufficeret si arcus quantumvis breves se tamen invicem intersecantes descripti essent: quod igitur in similibus palam casis fit. Non enim ex integris peripheriis, magis quod segmentis, procedit demonstratio.'
} 
Wallis, at any rate, voiced some dissatisfaction with diagrammatic inferences in other parts of his work on elementary geometry. Most relevantly of all, in his celebrated attempt to prove the Parallel Postulate, Wallis warned the reader that a rigorous demonstration of the theory of parallels could not be grounded on inferences drawn 'from the inspection of a diagram' (ex inspectu schematis). The latter claim had its relevance, of course, in the history of the discovery of non-Euclidean geometry (that was to require a remarkable effort in forsaking diagrammatic inferences), but in relation to Elements I, 1 Wallis seemed just to state that the intersection of the two circles, however evident from the diagram, should nonetheless be propositionally articulated. ${ }^{20}$

The need for a complete and at the same time economical system of principles, which would not indulge in repetitions and pleonasms, was a driving force of Giovanni Alfonso Borelli's (1608-1679) edition of the Elements, the Euclides restitutus (Pisa 1658). Borelli's aim was no less than a complete transformation of the axiomatic basis of elementary geometry: accordingly, he stood out as one of the very best and most prolific inventors of some quite well-crafted axioms. As a matter of fact, his treatment of Elements I, 1 remained for centuries the amplest and the most elegant discussion of this Euclidean construction. Borelli had one single principle (his Axiom 13) dealing with intersections:

If the same straight line is inside two figures, the two figures will have a common part and will intersect one another. ${ }^{21}$

The formulation is remarkable since it seems to move toward a more general formulation of continuity in which a mereological element (the common part) merges with a few fully-fledged topological notions (such as the reference to the interior of the figure, which aims at excluding the possibility that the two figures could have just a boundary in common). From a modern point of view, Borelli's principle sounds at the same time too weak and too strong, since the existence of a part common to the two figures seems to be trivial in several understandings of the notion of 'interior', and on the other hand it seems not to imply the intersection of the boundaries of the figures (which is the intended meaning of the last clause). In any case, Borelli gave no justification or further explanation for the axiom, and simply employed it in the proof of Elements I, 1.

A few years later, Borelli addressed the problem of intersections from a different point of view, as Richard had done before him. In 1679, he published a second, abridged edition of his masterwork, deleting the much-needed continuity axiom and hoping to be able to provide a proof of Elements I, 1 without it. In this work Borelli's main concern was to prove rigorously that the two circles in the Euclidean proof actually cross one another because of their relative positions, their actual meeting having probably to follow from the simple definition of figures as continuous quantities. Borelli insisted on the latter point by stressing the necessity of giving genetic definitions of the basic geometrical objects. In the

\footnotetext{
${ }^{20}$ Wallis's attempt at a proof of the Parallel Postulate was written at the time of the Praelectiones and was publicly presented in 1663 . It was only printed in 1693 , however, in an appendix to his Opera. The sentence on the use and abuse of diagrams can be read in John Wallis, 'De Postulato Quinto et Definitione Quinta Libri 6 Euclidis Disceptatio geometrica', in Wallis, Opera mathematica (Oxford: Theatrum Sheldonianum, 1693-9), vol. 2, p. 678.

${ }^{21}$ Giovanni Alfonso Borelli, Euclides restitutus (Pisa: Onofri, 1658), p. 14: 'XIII. Si eadem recta linea intra duas figuras tota collocata fuerit, habebunt illae figurae partem aliquam commune, \& se secabunt.'
} 
case of circles, for example, he gave a definition by the rotation of a segment around one of its ends, and then added an axiom stating that all the radii of a circle are equal (Euclid's original definition). In a sense, then, Borelli defined the circle through continuity (by means of motion), and simply characterized it as a figure with equal radii. Needless to say, in the lack of a clear notion of continuity the expedient cannot work. We may still appreciate Borelli's construction from 1679, for it offered a much better propositional proof of the overlapping of the circles than Richard's original (and still unpublished) demonstration. ${ }^{22}$

In the same years of the first edition of Borelli's work, and independently of it, Blaise Pascal (1623-62) left unfinished and unpublished an Introduction à la géométrie. In it, he listed several axioms, and then a few théorèmes connues naturellement, of which he gave no demonstrations. Among the latter, we find a very neat formulation of a Line-Line intersection principle:

If two points are taken on the different sides of a straight line, a straight line going from one point to the other will intersect the first line in one and only one point,

then a Line-Circle intersection principle:

An infinite straight line passing through a point inside a circle intersects the circumference in two and only two points,

and, finally, a Circle-Circle intersection principle:

A circumference passing through a point inside a circle and a point outside it intersects the circumference of the circle in two and only two points.

Pascal's Introduction to geometry, or at least what has survived of it, ends shortly after discussing the principles and does not take into consideration Euclid's propositions. An explicit treatment of Elements I, 1 in the light of these newly-introduced principles is therefore missing. ${ }^{23}$ Still, Pascal's principles are remarkable for their simplicity and represent a major advance compared to his predecessors', insofar as he did not get involved with the cumbersome notion of a 'figure' in general. Today's Line-Circle and Circle-Circle intersection axioms are in fact very close in formulation to Pascal's own principles.

Gilles Personne de Roberval (1602-75) may have had access to Pascal's papers, and elaborated a remarkable theory of intersections that also remained unpublished. In a set of notes aiming to provide a new foundation for geometry, on which he was working in the

\footnotetext{
${ }^{22}$ Borelli's discussion of the positional properties of the two circles in order to prove their crossing may come from Proclus's discussion of Elements I, 22, in which a demonstration of the fact that two circles in a certain position cross each other is given. Such a proof is quite natural in Elements I, 22, for Euclid gave some conditions on the lengths of the sides of a triangle in order to be able to carry out the construction, and the latter conditions may also be seen as requirements for the overlapping of the circles.

${ }^{23}$ The text is now available in Blaise Pascal, Oeuvres, ed. L. Brunschvicg, P. Boutroux and F. Gazier (Paris: Hachette, 1904-1914), vol. 9, p. 293: '8. S'il y a deux poincts l'un au deça, l'autre au delà d'une ligne droite, alors une ligne droite qui tend d'un point à l'autre coupe la ligne droite qui est entre deux, en un point et un seul. 9. La ligne droite infinite qui passe par un point qui soit au dedans d'un cercle coupe la circomference en deux point et deux seulement. 10. La circomference qui passe par deux points, l'un au dedans d'un autre cercle, et l'autre au dehors, le coupe en deux points et en deux seulement.'
} 
final years of his life, Roberval presented in fact as Postulate 3 of the Third Book the following:

If an infinite straight line passes inside a plane or a solid figure, it will go through the figure, and intersect the boundaries of the figure, and go further as far as one wants beyond the figure.

Added to this note of Roberval's is an annotation in another hand (possibly that of La Hire or Blondel, who kept and studied Roberval's manuscripts after his death), claiming that such a postulate is 'a corollary' of the nature of geometrical figures. Roberval himself, in fact, had defined a figure by the notion of extension, and extension by continuity. His definition of continuity, however, was rather standard and vague, calling 'continuous' any whole the parts of which are 'connected to one another'. While a good definition of continuity was still sorely lacking in the 1670s, Roberval's use of the axiom is noteworthy, since he employed it in discussing fourteen theorems on the various possible meetings of two circles, concluding with a fifteenth proposition: namely, the demonstration of Elements I, $1 .{ }^{24}$

\section{Leibniz and the eighteenth century}

A further important set of manuscripts on the topic are those by Gottfried Wilhelm Leibniz (1646-1716), who had the possibility of reading both Pascal's and Roberval's handwritten notes, and left a large number of reflections on the notion of continuity in elementary geometry. Leibniz's approach to the subject is unprecedented in the seventeenth century, for he was the only mathematician who attempted to work out a notion of continuity viable for geometry. ${ }^{25}$

Leibniz's studies on the calculus were clearly the main driving force behind his investigation of continuity, since they required a general understanding of this notion. It should be added that, in the few years that elapsed between the works of Richard and Borelli and the investigations of Leibniz, geometry had been extended to a far wider domain of objects than those dealt with in Euclid's Elements. A foundational solution provided for the geometry of the Elements might still have been conceived to be applicable to a few other cases extending beyond its ambit (such as Apollonius's conic sections, or perhaps Descartes's algebraic geometry). But it was clear that a discussion on continuity and intersections conducted at the end of the seventeenth century, and which aspired to ground the possibility of the new geometry emerging in this period, could not possibly be

\footnotetext{
${ }^{24}$ Roberval's unpublished work can now be read in the commented edition by Vincent Jullien, Eléments de géométrie de G.P. de Roberval (Paris: Vrin, 1996). The above-mentioned axiom is to be found, in this edition, on p. 161: 'Si une ligne droite indéfinie passé par dedans une figure plane ou solide, elle la traversera de part et d'autre et rencontrera les extrémités et elle passera outré si loin qu'on voudra, au delà de la figure'. The definition of continuity is on p. 93, and the demonstration of Elements I, 1 on pp. 166-7.

${ }^{25}$ For a fully-fledged account of Leibniz's views on continuity and intersections, see Vincenzo De Risi, 'Leibniz on the Continuity of Space', in Vincenzo De Risi, ed., Leibniz and the Structure of Sciences. Modern Perspectives on the History of Logic, Mathematics, Epistemology, Boston Studies in Philosophy and History of Science (Berlin: Springer 2019), 111-69.
} 
restricted to the narrow domain of circles and straight lines alone. Leibniz's foundational studies, in particular, aspired to provide a foundation for the whole of mathematics, not just elementary geometry. He could not thefore rest content with the 'Circle-Circle' or 'Line-Circle' intersection principles, but needed a fuller account of continuity. Yet Leibniz's amplest studies on continuity in geometry are to be found in his many unpublished commentaries and reading notes on Euclid's Elements.

Leibniz's own solution to the problem of intersections is first presented in an essay from the mid-1690s, the Specimen geometriae luciferae, in which he attempted a general definition of continuity that could be viable in elementary geometry:

A continuum is a whole, any two of the co-integrating parts of which (i.e. parts which, taken together, coincide with the whole) have something in common, and such indeed that, in the case where the parts are not redundant and have no common part, i.e. when the sum of their magnitudes is equal to the total magnitude, they have at least a boundary in common. ${ }^{26}$

This was a mathematical reworking of the Aristotelian definition of continuity, that passed through exact formal definitions of all the terms involved (whole and parts, magnitude, boundary). Leibniz even attempted a symbolic expression of the new definition of continuity, by means of his geometrical formalism (what he called the characteristica geometrica). Immediately after having provided such a definition of continuity, he attempted to show how to apply it to the demonstration of Elements I, 1, and furthermore in general to ground any Circle-Circle or Line-Circle intersection principles. For instance:

Moreover, it follows from the nature of continuity that every continuum which is partly inside and partly outside a figure falls on its boundary. In fact, any two parts of a continuum that together make the whole have something in common even though they have no part in common. Let there be, then, two parts of a straight line, one inside and the other outside the circle. They have a common point. This point is also common to the circle, for it is in the part of the plane falling inside the circle and also in the part of the plane in which the straight line falling outside the circle lies. But anything that is common to the two parts of the plane, is in their common section, that is, the circumference. ${ }^{27}$

It scarcely need to be noted that Leibniz's very elaborate demonstration completely avoided reference to diagrams. Leibniz, in fact, was one of the most important advocates, in the seventeenth century, of a purely propositional treatment of geometry.

While Pascal's, Roberval's and Leibniz's papers may have not exerted a significant influence on the further development of geometry, Richard's and Borelli's intersection principles were sufficiently well known to engender further discussions and even the inclusion of them in textbooks for students. It may be said that thanks to their works, in the second half of the seventeenth century intersection axioms had become widespread in

\footnotetext{
${ }^{26}$ G.W. Leibniz, Mathematische Schriften, ed. G.J. Gerhardt (Berlin/Halle: Asher/Schmidt, 1849-63), vol. 7, p. 284 .

${ }^{27}$ While Leibniz discussed the intersection of circles in the Specimen, I take this quotation, in fact, from another Leibnizian commentary on the Elements: the In Euclidis $\pi \rho \tilde{\omega} \tau \alpha$ of 1712 (Leibniz, Mathematische Schriften, vol. 5, p. 196).
} 
foundational discussions on elementary geometry. In the following century, the main textbooks on geometry still continued to employ ad hoc intersection principles, taking as a model the foundational discussion of the previous years. We will not follow in any detail these later developments, for they added nothing new to the previous studies, and only attempted to simplify or systematize those researches to better transmit them to the new generations.

By way of example, however, we may point to a few of these works. In Germany, a tradition of textbooks may well have been initiated by the Jesuit professor Caspar Schott (1608-66), who included a Circle-Circle intersection axiom in his encyclopaedic treatise on science (Würzburg 1661). ${ }^{28} \mathrm{~A}$ few decades later, the philosopher and mathematician Christian Wolff (1679-1754) offered in his works for the schools a purely philosophical definition of continuity, which was reminiscent of Aristotle's. Wolff was unable to employ it in his proof of Elements I, 1, and thus he rather provided a supplementary proof (probably taken from Borelli) that the two circles in Elements I, 1 are in such positions as to overlap and, without mentioning continuity, stated that they intersect. ${ }^{29}$ The mathematician Abraham Gotthelf Kästner (1719-1800), in his celebrated Anfangsgründe der Geometrie (Göttingen 1758), also gave a very general definition of continuity, which had no further use in the text, and in order to prove Elements I, 1, he instead had recourse to the usual Line-Circle Axiom. ${ }^{30}$

In Britain, on the other hand, the important edition of Euclid (London 1747) by Thomas Simpson (1710-1761) grounded the intersection of the circles in Elements I, 1 not even in an ad hoc axiom but rather in a definition, stating that 'Two circles are said to cut one another, when they fall partly within, and partly without each other'. ${ }^{31}$ But still in 1828, Dionysius Lardner's edition of Euclid commented that the intersection of the circles in Elements I, 1 is self-evident, given that they are defined as continuous lines. No definition of continuity, however, is attempted in this book. ${ }^{32}$

The situation was quite different, of course, outside of the domain of elementary geometry. Here, continuity was a hotly debated topic, since it represented one of the most delicate foundational problems of analysis. Since higher analysis in the eighteenth century was still treated very much geometrically, it was not uncommon for purely analytical questions about continuous functions to merge with (often naïve) geometrical notions of

\footnotetext{
${ }^{28}$ Caspar Schott, Cursus mathematicus, sive Absoluta omnium mathematicarum disciplinarum encyclopaedia (Würzburg: Hertz, 1661), p. 65: '26. Circuli ex diversis ejusdem intervalli extremis tanquam centris descripti, intersecant se mutuo.'

${ }^{29}$ Wolff s definition of continuity is to be found in $\$ 554$ of his Philosophia prima sive Ontologia (Frankfurt a.M./Leipzig: Renger, 1729, 1736), pp. 432-3. Wolffs discussion of Elements I, 1 is to be found in $₫ 197$ of the first volume of his Elementa matheseos universae (Halle: Renger, 1713, 1730), p. 147.

${ }^{30}$ Abraham Gotthelf Kästner, Anfangsgründe der Arithmetik, Geometrie, ebenen und sphärischen Trigonometrie und Perspectiv (Göttingen: Vandenhoeck, 1758, 1786): see page 165 for the definition of continuity, p. 178 for his Line-Circle intersection axiom (Axiom 7), and pp. 179-80 for his proof of Elements I, 1.

31 Thomas Simpson, Elements of plane geometry (London: Farrer, 1747). The definition of a circle is on page 43, and the proof of Elements I, 1 appears at Book 3, Theorem 8: p. 49.

${ }^{32}$ Dionysius Lardner, The first Six Books of the Elements of Euclid (London: Taylor, 1828), 14 footnote: 'In the solution of this problem it is assumed that the two circles intersect, inasmuch as the vertex of the equilateral triangle is a point of intersection. This, however, is sufficiently evident if it be considered that a circle is a continued line which includes space, and that in the present instance each circle passing through the centre of the other must have a part of its circumference within that other, and a part without it, and must therefore intersect it.'
} 
continuity. The most evident example of this is probably the Intermediate Value Theorem, which was often regarded as a proposition about the intersection points of a curve (the graph of the function) with a straight line (the $x$-axis). Its eighteenth-century proofs, including a famous one attempted by the aforementioned Kästner, blended subtle analytic arguments with certain unwarranted assumptions regarding the existence of the intersection points, given the continuity of the lines and their relative position in the plane. Bolzano's celebrated demonstration of the theorem was achieved by stressing the necessity of a certain purity of method in obtaining such results, which (he argued) should not have recourse to any geometrical considerations. ${ }^{33}$

The grounding of the continuity of space itself, therefore, had to wait for a roundabout historical path that passed through the foundations of analysis and, later on, the definition of completeness in the domain of real numbers. In this respect, we see that the first thematization of continuity in geometry required the introduction of the notion of space, whereas its final formulation prompted the abandonment of spatial considerations and a move toward even more abstract fields. These developments, however, required a completely different understanding of the role and aims of mathematics, and find no place in the history of elementary geometry. It comes then as no surprise that, at the end of this story, Hilbert felt that the modern notion of continuity (as completeness) was a threat for the purity of method in geometry, and that he did not recognize such a notion as a legitimate heir of Euclid's geometry.

\footnotetext{
${ }^{33}$ Kästner's still half-geometrical proof of the Intermediate Value Theorem is to be read in his Anfangsgründe der Analysis endlicher Größen (Göttingen: Vandenhoeck, 1759, 1794), \$316, pp. 198-9. Bolzano’s proof, along with a general discussion on the purity of analytical methods, is to be found in his famous Rein analytischer Beweis ... (Prague: Haase, 1817). For a few hints on the development of this theorem, and a comprehensive view on the interplay between geometry and analysis in the foundations of mathematics during the eighteenth century, see Gert Schubring, Conflicts between Generalization, Rigor, and Intuition. Number Concepts Underlying the Development of Analysis in 17-19th Century France and Germany (Berlin: Springer 2005). For a comparison between Elements I, 1 and Bolzano's theorem, see Marcus Giaquinto, 'Crossing Curves: A Limit to the Use of Diagrams in Proofs', Philosophia Mathematica, 19 (2011): pp. 281307.
}

I would like to thank all the participants to the workshops held in Oxford in 2017 and 2018 on 'Reading Euclid in the Early Modern World', who have provided me with invaluable advice for the development of this essay. I am also grateful to the Logic and Philosophy of Science Department of the University of California, Irvine, where I was able to spend two months in 2018, in which I polished the present essay and had the opportunity to have an important feedback on my researches. I am especially thankful to Mattia Mantovani, who offered me detailed remarks and helpful insights, substantially improving the final version of this essay. Finally, I thank Philip Beeley for having provided me with a copy of Wallis's manuscripts on Euclid, and Antoni Malet for having directed me to the manuscripts of Claude Richard in Madrid. 